\title{
Single umbilical artery with associated anomalies at perinatal autopsy
}

\author{
Anita A.M1 ${ }^{1}$ Pratima Manohar Pattar 2,*, Anuradha G. Patil ${ }^{3}$, Jyotirling Savale ${ }^{4}$, Megha Kamalapurkar \\ ${ }^{1}$ Associate Professor, ${ }^{2}$ Resident, ${ }^{3}$ Professor and HOD, ${ }^{4}$ Assistant Professor, Dept. of Pathology, M.R. Medical College, \\ Kalaburagi, Karnataka, ${ }^{5}$ Gynaecologist, Dept. of Gynaecology, Devata Hospital, Kalaburagi, Karnataka, India
}

*Corresponding Author:

Email: pratimapattar@gmail.com

\begin{abstract}
Introduction: Single umbilical artery (SUA) is one of the congenital anomalies, with a birth incidence of about $0.2-1.2 \%$. It may accompany other abnormalities or occur as an isolated defect. The aim of the study was to estimate the association between SUA and other birth defects in a series of perinatal autopsies.

Materials and Methods: We evaluated 322 fetuses sent for autopsy from June 2016 to December 2017 at M.R. Medical College, Kalaburagi.

Results: Of 322, ten fetuses (3.12\%) had single umbilical artery. Among which 6 cases were associated with urinary anomalies, 1 case with associated cardiac anomaly, 1 case of inencephaly and 2 were of isolated SUA defect.

Conclusion: Single umbilical artery is commonly associated with other congenital anomalies and it has a strong association with urinary anomalies.
\end{abstract}

Keywords: Single umbilical artery, Perinatal autopsy, Congenital anomalies, Urinary anomalies.

\section{Introduction}

Single umbilical artery is one of the common congenital anomalies with a reported incidence of 0.2 $1.2 \%$ in live newborns. ${ }^{1}$ The incidence is higher among twins, fetal deaths, abortuses and autopsies. ${ }^{2,3}$ The rate of associated congenital anomalies with single umbilical artery is about $10 \%$ as reported by a National Registry. ${ }^{4}$

Single umbilical artery is detectable by ultrasound after about 13 gestational weeks, and it can be found in healthy newborns, but its prevalence is 3 to 4 times higher in infants with fetal growth restriction, prematurity, perinatal death, and twinning. ${ }^{3}$ It has also been associated with maternal diabetes, preeclampsia, and poli- and oligohydramnios, ${ }^{1,2}$ and its prevalence is about 4 times higher in autopsy reports ${ }^{3}$ or when other birth defectss ${ }^{2,4-6}$ are present. However, it is important to look for other associated anomalies when single umbilical artery is diagnosed antenatally or postnatally.

SUA, occurring as a solitary malformation, is compatible with postnatal life. ${ }^{1}$ However, the increased incidence of SUA in low birth weight infants suggests that this anomaly exerts a deleterious effect on the intra- uterine growth of the fetus. ${ }^{1,2}$ Although SUA may coexist with a variety of abnormalities, it has been found particularly in association with malformations of the renal, skeletal, gastrointestinal, cardiovascular, and central nervous systems. ${ }^{5-8}$

We here present observations on the types of congenital malformations found in association with SUA on perinatal autopsies.

\section{Materials and Methods}

We examined 322 fetuses which were sent for autopsy from June 2016 to December 2017, at M.R. Medical College, Kalaburagi. These fetuses were either aborted due to intrauterine death or after prenatal detection of a malformation. The gestational age of the fetuses ranged from 14 to 38 weeks.

Proportions were compared using a chi-square test. The risk for each selected birth defect associated with SUA was expressed in terms of the odds ratio (OR) and its $95 \%$ confidence interval $(95 \% \mathrm{CI})$. All analyses were performed with computer software SPSS 22.0 version.

\section{Result}

We examined 322 fetuses and the gestational age ranged between 14 and 38 weeks and the birth weight between $150 \mathrm{~g}$ and $3400 \mathrm{~g}$. We found single umbilical artery in $3.1 \%$ (Table 1) of the autopsies (10 cases) and as a single anomaly in $0.6 \%$ (2 cases). Out of these 10 cases, 8 cases were associated with other congenital anomalies. Majority of the cases (i.e 6 cases) were associated with urinary anomalies (Fig. 1 \& 2), 1 case of associated inencephaly (Fig. 3) and 1 case of cardiac anomaly (Fig. 4) as shown in table 2. Among these there were also 2 cases of mermaid syndrome or syrenomelia with SUA (Fig. 5).

The overall birth defect prevalence in association with SUA was $80 \%$ ((OR 20.47; 95\% CI, 4.2-99.2; P $<0.001)$. Urinary tract anomalies predominated among the former, followed by cardiovascular and CNS defects. A preferential association with SUA was only found for urinary tract anomalies (OR 57; 95\% CI; P $<0.001)$. 


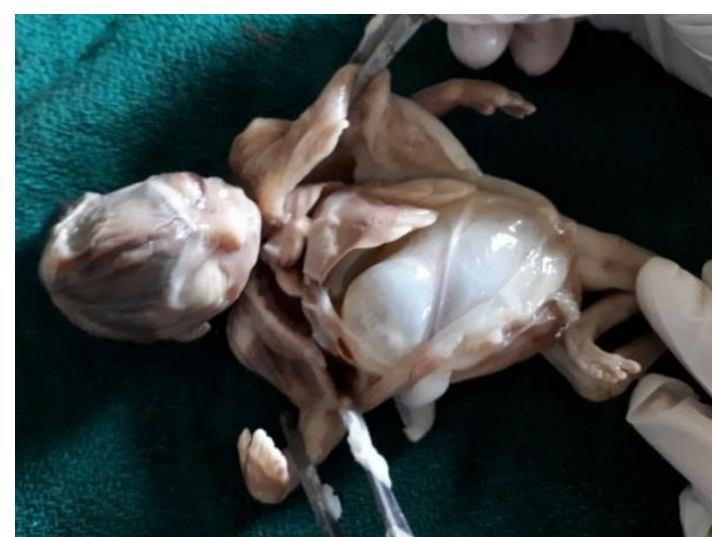

Fig. 1: Gross picture of fetus with megacystis

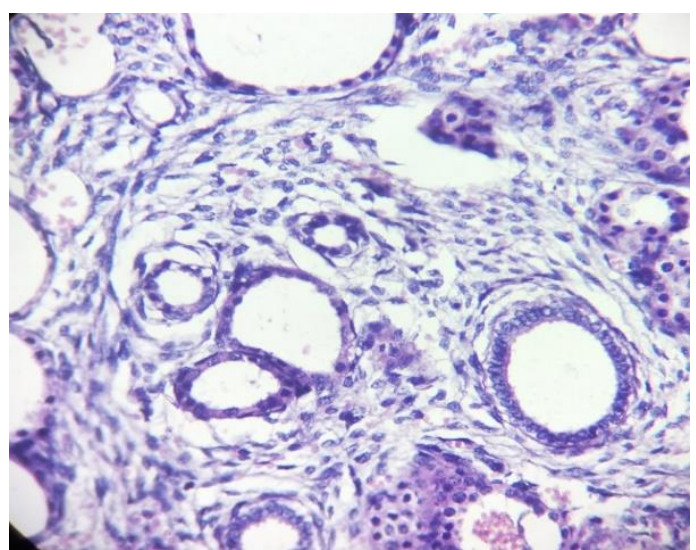

Fig. 2: H \& E 40x; showing primitive tubules \& ducts lined by cuboidal epithelium surrounded by mesenchymal tissue

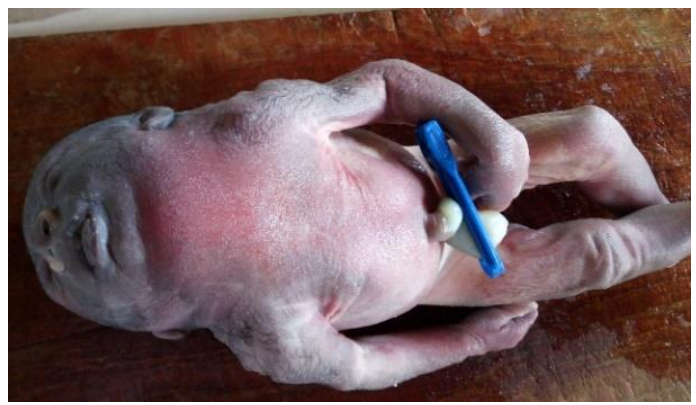

Fig. 3: Gross picture of inencephaly

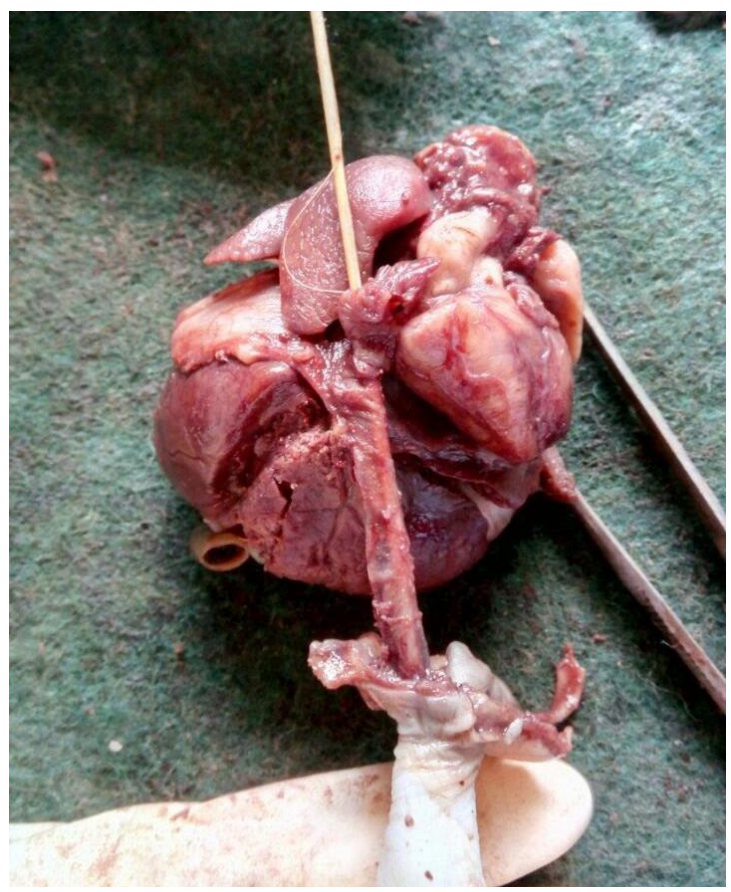

Fig. 4: Gross picture showing absent ductus venosus

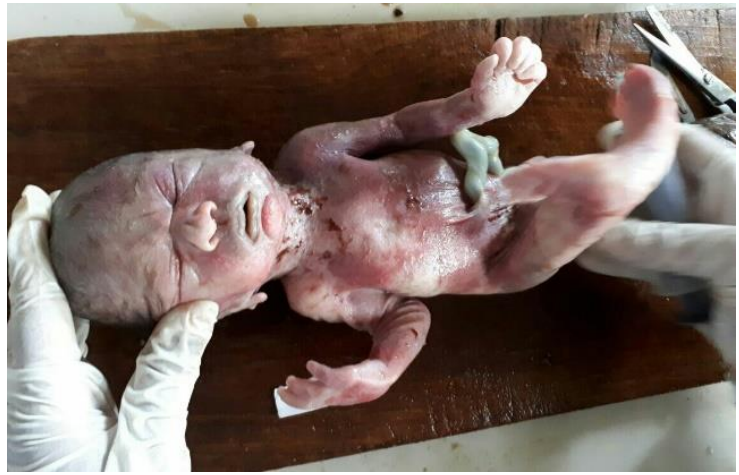

Fig. 5: Gross picture of Mermaid syndrome

Table 1: Showing details of cases with congenital anomalies

\begin{tabular}{|l|c|c|}
\hline Congenital anomalies & With SUA & Without SUA \\
\hline Nervous system anomalies & 01 & 24 \\
\hline Urinary anomalies & 06 & 08 \\
\hline Lung anomalies & - & 08 \\
\hline Cardiovascular anomalies & 01 & 03 \\
\hline GIT anomalies & - & 04 \\
\hline Musculoskeletal anomalies & - & 04 \\
\hline Total & $\mathbf{0 8}$ & $\mathbf{5 1}$ \\
\hline
\end{tabular}

(SUA: Single Umbilical artery) 
Table 2: Showing details of all 10 cases of SUA.

\begin{tabular}{|l|c|c|c|c|}
\hline S. No & Gestational age & $\begin{array}{c}\text { Birth } \\
\text { weight }\end{array}$ & $\begin{array}{c}\text { Mode of } \\
\text { death }\end{array}$ & Associated anomalies \\
\hline 1. & $32 \mathrm{wks}$ & $1200 \mathrm{~g}$ & IUD & $\begin{array}{c}\text { Left renal agenesis with B/L CCAM type-2 and } \\
\text { diaphragmatic hernia }\end{array}$ \\
\hline 2. & $28 \mathrm{wks}$ & $1000 \mathrm{~g}$ & IUD & Mermaid syndrome with B/L renal agenesis \\
\hline 3. & $26 \mathrm{wks}$ & $900 \mathrm{~g}$ & IUD & $\begin{array}{c}\text { Renal-Hepatic-Pancreatic dysplasia (RHPD) with } \\
\text { asplenia }\end{array}$ \\
\hline 4. & $27 \mathrm{wks}$ & $1000 \mathrm{~g}$ & IUD & Inencephaly \\
\hline 5. & $14 \mathrm{wks}$ & $100 \mathrm{~g}$ & IUD & Left renal hypoplasia with ventriculomegaly \\
\hline 6. & $38 \mathrm{wks}$ & $3500 \mathrm{~g}$ & IUD & $\begin{array}{c}\text { Absent ductus venosus with overriding of aorta, right } \\
\text { ventricular hypertrophy and pulmonary stenosis }\end{array}$ \\
\hline 7. & $28 \mathrm{wks}$ & $1500 \mathrm{~g}$ & Termination & \\
\hline 8. & $22 \mathrm{wks}$ & $1200 \mathrm{~g}$ & Termination & $\begin{array}{c}\text { Mermaid syndrome with left multicystic dysplastic } \\
\text { kidney and right renal agenesis }\end{array}$ \\
\hline 9. & $14 \mathrm{wks}$ & $300 \mathrm{~g}$ & Termination & Megacystis \\
\hline 10. & $28 \mathrm{wks}$ & $1000 \mathrm{~g}$ & IUD & - \\
\hline
\end{tabular}

\section{Discussion}

Perinatal mortality of SUA infants is related to associated fetal malformations, prematurity, low birthweight and intra-uterine growth retardation. Although associated malformations are the primary cause of the high perinatal mortality, even nonmalformed SUA infants have an increased mortality rate. $^{4}$

It is clear from the literature that SUA is more often found in association with a wide range of other malformations than as an isolated defect, but there is no agreement as to whether preferential associations with particular types of defects exist. ${ }^{3}$

The reported incidence in the literature of congenital malformations in SUA infants vanes between $18.4 \%$ and $68 \%$, in prospective studies. In our study the incidence was $80 \%$. It was well correlated with study by Rittler et al $^{3}$ Eighty-three percent of SUA cases involved other malformations and $81 \%$ reported by Heifetz ${ }^{6}$ in an autopsy series but much higher than the $53 \%$ reported by Froehlich and Fujikura, ${ }^{5}$ probably because of methodological differences.

Peckham and Yerushalmy's ${ }^{8}$ prospective study also included a control group; they found that the incidence of congenital malformations in children with three vessels was $1.15 \%$ and in SUA infants $20.4 \%{ }^{4}$ In our study the incidence in control group is $15.8 \%$ and in SUA infants is $80 \%$. In a study by Lilja et $\mathrm{al}^{4}$ found that the overall risk of malformation in SUA infants is increased 4.3 times. In our study we found the risk to be increased 20.4 times.

In a study by Rittler et $\mathrm{al}^{3}{ }^{3}$ excluding bilateral kidney agenesis and other severe urinary tract anomalies, close to $10 \%$ of the cases with SUA still showed a mild to moderate urinary defect, which was probably not the primary cause of death. The present results showed that $60 \%$ of the cases involving SUA had a urinary anomaly of varying degrees of severity and that the risk for this type of birth defects was 57 times higher if SUA was present than if it was absent.

\section{Conclusion}

Single umbilical artery has incidence of $3.1 \%$. It is commonly associated with other congenital anomalies and it has a strong association with urinary anomalies.

\section{References}

1. Csecsei K, Kovacs T, Hinchliffe SA, Papp Z. Incidence and associations of single umbilical artery in prenatally diagnosed malformed, midtrimester fetuses: A review of 62 cases. Am J Med Genet. 1992;43:524-30.

2. Nayak S, Shukla A, Girisha M. Anomalies Associated with Single Umbilical Artery at Perinatal Autopsy. Indian pediatrics. 2015, Volume 52.

3. Rittler M, Mazzitelli N, Fuksman R, Garci L, and Grandi C. Single Umbilical Artery and Associated

Malformations in Over 5500 Autopsies: Relevance for Perinatal Management. Pediatric and Developmental Pathology. 2010;13:465-470.

4. Lilja M. Infants with single umbilical artery studied in a national registry. 2: Survival and malformations in infants with single umbilical artery. Paediatric and Perinatal Epidemiology. 1992;6:416-422

5. Froehlich L, Fujikura T. Follow-up of infants with single umbilical artery. Pediatrics. 1973;52:6-13.

6. Heifetz SA. Single umbilical artery: a statistical analysis of 237 autopsy cases and review of the literature. Perspect Pediatr Pathol. 1984;8:345-378.

7. Persutte YM, Hobbins J. Single umbilical artery: a clinical enigma in modern prenatal diagnosis. Ultrasound Obstet Gynecol. 1995;6:216-229.

8. Peckham, C.H., Yerushalmy, J. Aplasia of one umbilical artery: incidence by race and certain obstetric factors. Obstetrics and Gynecology. 1965;26359-366.

How to cite this article: Anita AM, Pattar PM, Patil AG, Savale J, Kamalapurkar M. Single umbilical artery with associated anomalies at perinatal autopsy. J Diagn Pathol Oncol. 2018;4(3):177-179. 